\title{
External and Environmental Radiation Dosimetry with Optically Stimulated Luminescent Detection Device Developed at the SCK·CEN
}

\author{
Reinhard Boons, Mark Van Iersel, Jean Louis Genicot* \\ Radiation Dosimetry and Calibration-Environmental Health and Safety \\ SCK-CEN, Belgian Nuclear Research Center, Mol, Belgium \\ Email: ${ }^{*}$ jgenicot@sckcen.be
}

Received September 9, 2011; revised October 22, 2011; accepted November 23, 2011

\begin{abstract}
The laboratory of Radiation Dosimetry and Calibration of the Belgian Nuclear Research Centre (SCK CEN) is using thermoluminescence dosimetry for more than thirty years for routine measurements and for R \& D investigations. In 2002, it has developed an experimental device based on the optically stimulated luminescence (OSL) technique. This device is working with $\mathrm{AL}_{2} \mathrm{O}_{3}: \mathrm{C}$ crystals stimulated by the green line $(488 \mathrm{~nm})$ emitted by a $150 \mathrm{~mW}$ argon laser. This paper describes this device, its characteristics, some applications in space dosimetry and the R \& D works initiated in this field during the next few years.
\end{abstract}

Keywords: External Dosimetry; OSL; Optically Stimulated Dosimetry

\section{Introduction}

Luminescence applied to radiation dosimetry is used in research in different application fields (geology, dating, radiotherapy, retrospective dosimetry, space dosimetry $\cdots$ ). SCK $\cdot$ CEN is using thermoluminescence detectors (TLD) for more than 30 years for routine control of the personal professionally exposed to ionizing radiations. The optically stimulated luminescence (OSL) technique also has been initiated in 2002 at the SCK.CEN for the same applications. A facility, using an argon laser has been developed to ensure the most versatile capabilities in the measurement of doses in different area with the best detection limits. This prototype device has been conceived in its first design by Dr. O. Goossens.

The main purpose of this R \& D study was to extend the capabilities of the laboratory by taking profit of the different characteristics of the OSL detectors: their large dynamic range, their better sensitivity and reusability, their low fading and particularly the easy way they are used in comparison with the TLD techniques. The $\mathrm{Al}_{2} \mathrm{O}_{3}$ : C crystal was chosen as first material to study the OSL techniques.

Taking part in different space research programs, the SCK.CEN enforced the laboratory to enlarge the number of detector types to optimize the measurement of absorbed and equivalent doses in the radiation environment found in the International Space Station [1].

"Corresponding author.

\section{Description of the Laboratory for External Dosimetry}

When the first Belgian Reactor BR1 became operational in 1956, the film dosemeter was used to measure the effective doses to the body, the skin and the fingers in case of irradiation with $\gamma-, \mathrm{X}-, \beta$-rays and neutrons and also in case of criticality accident. After modification of the film badge design, this technique has been used routinely until 1986 when it was replaced by the thermoluminescence detector (TLD) using three LiF crystals in a one-inch diameter plastic box. The main advantages of the TLD was a larger dynamic range, extending the irradiation period to one month instead of one week and an easier technique to read the detectors. The TLD technique is used today for routine measurements and accepted as legal mean for external dose assessments.

Each of the three LiF detectors (model TLD-100 also called MTS type) is measured by counting the light emitted when the crystal is heated to a constant temperature of $190^{\circ} \mathrm{C}$ during 13 seconds. The measurements are performed with an "Automatic TLD reader 4000" developed by NRG-Re in Arnhem, Netherlands. More than 6600 detectors batches are measured every month.

The TLD techniques have some limitations: the information is completely lost after the reading and the temperature required to read a detector depends on the detector type and can be high $\left(>400^{\circ} \mathrm{C}\right)$. The measurement must be done with a photomultiplier in a special place 
protected from ambient light. The Teflon ${ }^{\mathrm{TM}}$ TLD and the MOSFET active detector are also used for special applications.

\section{Requirements for OSL Dosimetry}

The development of optically stimulated luminescence (OSL) techniques has been initiated at the SCK.CEN in 2002. The main purpose of this R \& D work was to extend the capabilities of the laboratory by taking profit of the different advantages of this technique: larger dynamic range, better sensitivity and reusability (it was observed that TLD's can lose their sensitivity after repeated use, a default attributable to a redistribution of the impurities in the lattice after several thermal treatments of the crystal). The OSL technique is also easy to use.

The first crystal for OSL proposed by A. Romanovski in 1955 [2] was $\mathrm{SrS}: \mathrm{Eu}, \mathrm{Sm}$. The $\mathrm{Al}_{2} \mathrm{O}_{3}: \mathrm{C}$ crystal has been chosen as a study material because of different advantages. It can be used in TL mode and is 30 to 60 times more sensitive than TLD-100 [3]. $\mathrm{Al}_{2} \mathrm{O}_{3}: \mathrm{C}$ is several times more sensitive in OSL than in TL [4].

Other parameters required for OSL dosimetry are the reproducibility, the stability, the linearity and the dose-rate independence [5]. In OSL materials, the dose dependence is first linear, followed by an approach to saturation. Assuming no dose-rate effects, one can calibrate the sample at high dose-rates and deduce the dose collected at a much lower rate. The stability of the stimulation light source and of the light sensitive device (e.g. the photomultiplier tube) is also important.

OSL presents other advantages over TL: the heating of the sample is not necessary, avoiding the blackbody radiation; they do not exhibit thermal quenching of luminescence and their sensitization effect is significantly less in OSL. A problem is present with $\mathrm{Al}_{2} \mathrm{O}_{3}$ : $\mathrm{C}$ : each reading remove $0.2 \%$ of signal sensitivity so that the detectors are always recalibrated after each measurement.

\section{Descriptions of the Experimental Set-Up}

\subsection{General Description}

$\mathrm{An}^{+}{ }^{+}$laser (model Melles Griot 35 LAP 431) with a light output power of $150 \mathrm{~mW}$ has been chosen as stimulating light source (Figure 1). The optimum stimulation wavelength for $\alpha-\mathrm{Al}_{2} \mathrm{O}_{3}: \mathrm{C}$ is $480 \mathrm{~nm}$ and the $\mathrm{Ar}^{+}$laser is able to generate an output at $488.8 \mathrm{~nm}$ and another one ay $515.70 \mathrm{~nm}$. The second (green) wavelength has been selected because special effects may appear when blue light is used in OSL dosimetry [6]. The light output power of the laser is constant $(150 \mathrm{~mW})$ but the light stimulating the detector can be reduced by placing a neutral filter just before the crystal to minimize the scattering.

An electrical shutter is placed just after the laser module (part A) followed by a long pass filter. The laser beam

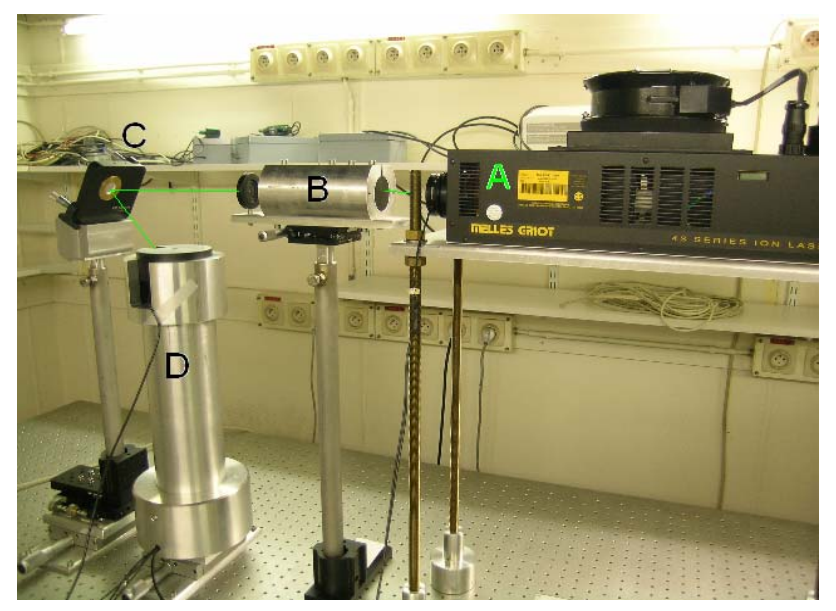

Figure 1. Layout of the OSL facility (A: Ar laser-B: Beam expender C: Mirror-D: tube with detector support, optics and PMT).

diameter, too small for the purpose $(0.72 \mathrm{~mm})$, is increased to $3.05 \mathrm{~mm}$ with a plano-concave lens followed by a confocal plano-convex lens.

The laser beam is reflected by a surface mirror to the sample placed on a quartz window above the detection module: the detector crystal emits a quite narrow light spectrum centered at $420 \mathrm{~nm}$ which is measured by a photomultiplier tube (PMT) with appropriate filters.

The photomultiplier tube is placed in a vertical aluminum tube to be protected from the external light except from the quartz window on top of the aluminum tube. Between the quartz window and the PMT, plano-concave and plano-convex lenses modify the shape and the size of the stimulated light emitted by the detector sothat the photocathode of the photomultiplier is completely illuminated. A filter pack eliminates the parasitic light and an electric shutter, placed before the PMT, protects it between measurements (Figure 2). With the aid of a microcontroller (ST62E20), this shutter is first opened and $0.3 \mathrm{~s}$ later the laser's shutter is opened to stimulate the detector. When the preset counting time is reached, both shutters are closed together.

A parabolic mirror, above the detector crystal reflects the useful light emitted upwards by the detector back to the PMT. This mirror is slightly ex-centered to avoid redirecting the light to the detector. The typical result of an OSL measurement is presented in Figure 3.

\subsection{Detection Limits}

The detection limit (a posteriori) is defined as:

$$
L L D=\frac{3 \cdot \sigma}{C} \cdot D
$$

where $\sigma=$ standard deviation on the background count; $C$ $=$ maximum counts of the measurement during the calibration; $D=$ Dose used for the calibration (Gy). 


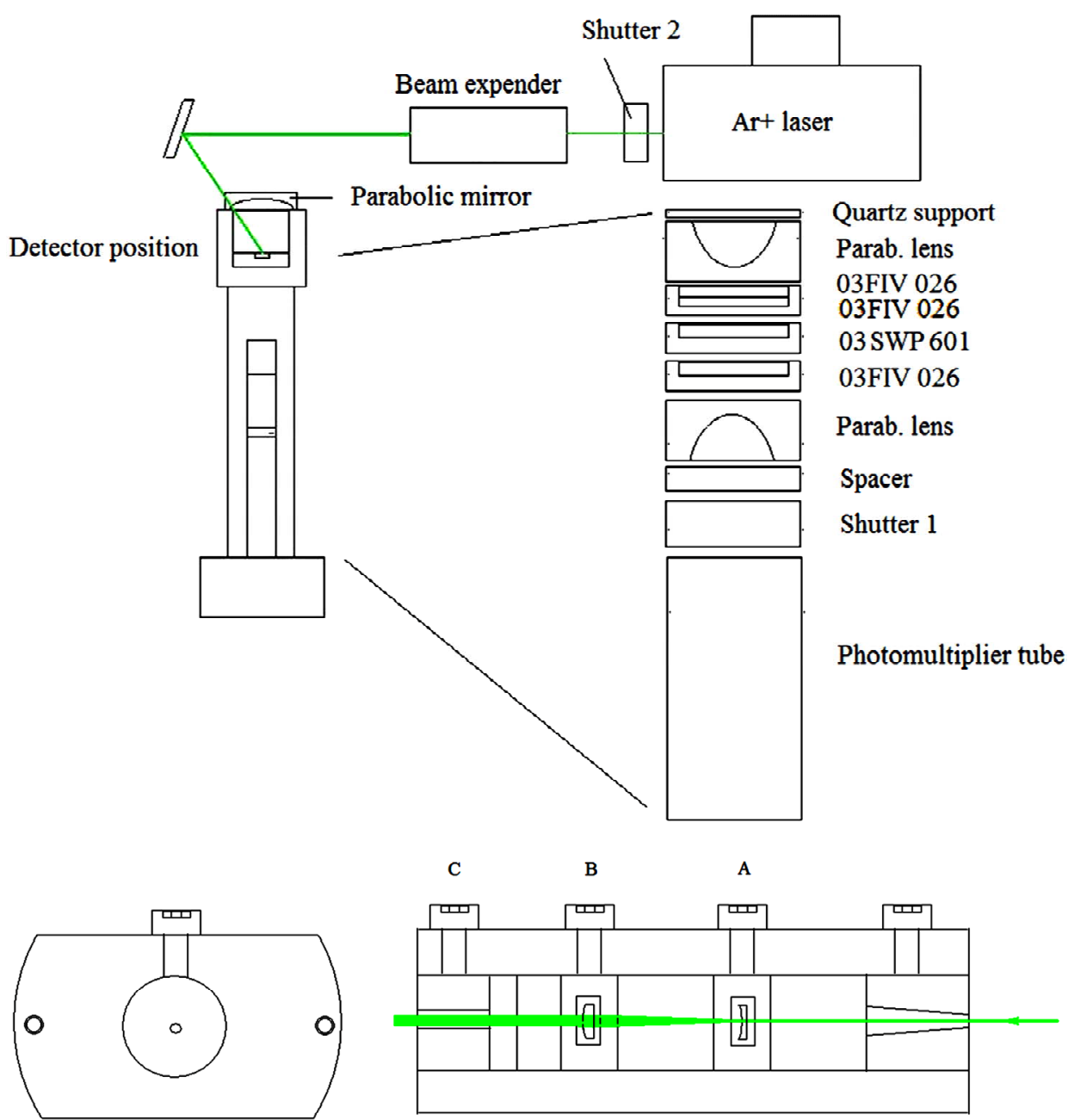

Figure 2. Layout of the OSL device using an $\mathrm{Ar}^{+}$Laser and details of the beam expender.

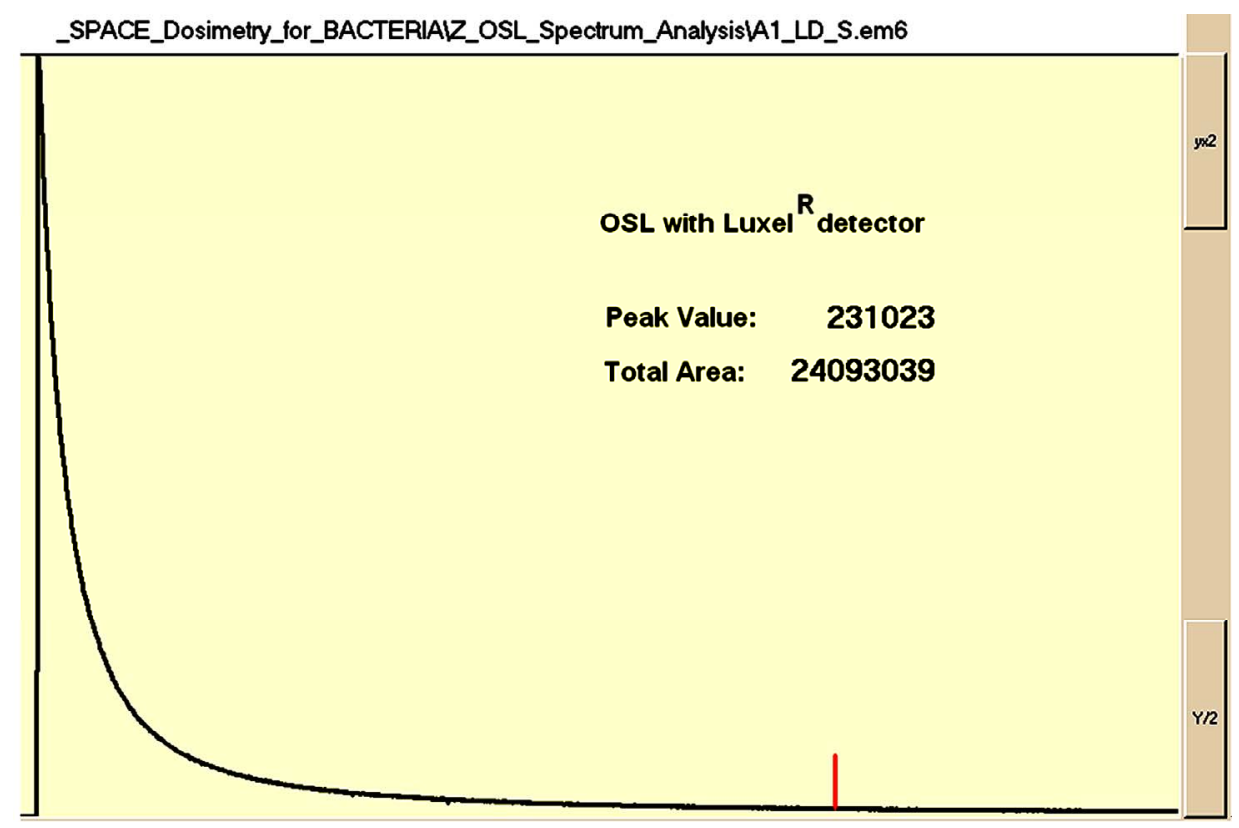

Figure 3. Result of OSL measurement (Luxel ${ }^{\mathrm{TM}}$ detector, Gamma irradiation from ${ }^{137}$ Cs source). 
This $L L D$ is determined with the method developed by McKeever et al. [7].

\subsection{Detectors Used in OSL}

Two types of detectors are presently used in the laboratory: TLD-500 and Luxel ${ }^{\mathrm{TM}}$. The TLD-500 is a $\alpha-\mathrm{Al}_{2} \mathrm{O}_{3}: \mathrm{C}$ mono-crystal. Before irradiation, this detector is annealed at $400^{\circ} \mathrm{C}$ during 60 minutes. After growth, the ingot of $\alpha$ $\mathrm{Al}_{2} \mathrm{O}_{3}: \mathrm{C}$ is cut in crystal about $1 \mathrm{~mm}$ thick. This leads to discrepancies in the thickness, weight and transparency of the different detectors. The individual mass and transparency of 78 different crystals have been measured (Figures 4 and 5). These discrepancies lead to the necessity to use an "individual factor" defined as:

$$
I F_{i}=\frac{S_{i}}{\frac{1}{n} \sum_{i=1}^{n} S_{i}}
$$

$S_{i}$ is the count measured during the illumination of detector $i$ and $\mathrm{n}$ is the number of detectors in the lot. Measurements show that the IF can vary from 0.55 to 2.04 for TLD-500.

The detector, with the trademark Luxel ${ }^{\mathrm{TM}}$, is a polycrystalline form of the same material glued between two sheets of plastic (Ertalon ${ }^{\mathrm{TM}}$ ). This Luxel ${ }^{\mathrm{TM}}$ is easily bleached with exposition to daylight: the residual dose information is reduced to $1.2 \%$ after 12 hours and to $0.21 \%$ after 24 hours. The light transmittance of the Luxel ${ }^{\mathrm{TM}}$ is shown in Figure 6.
The transmittance of the detector is defined as the ratio between the measurement of a monochromatic light beam (from an L.E.D.) in a defined geometry and the same measurement when the detector is placed between the light source and the detector. The device to measure the transmittance is shown in Figure 7. An L.E.D. selected for its wavelength is connected to a constant current generator controlled by the computer via a USB connection card (K8055 from Velleman ${ }^{\circledR}$ ). The transmitted light is measured with a TSL230 (fromTAOS) through a Propeller microcontroller array from Parallax ${ }^{\circledR}$. The value for $\mathrm{Al}_{2} \mathrm{O}_{3}: \mathrm{C}$ is calculated from 50 measurements for each wavelength.

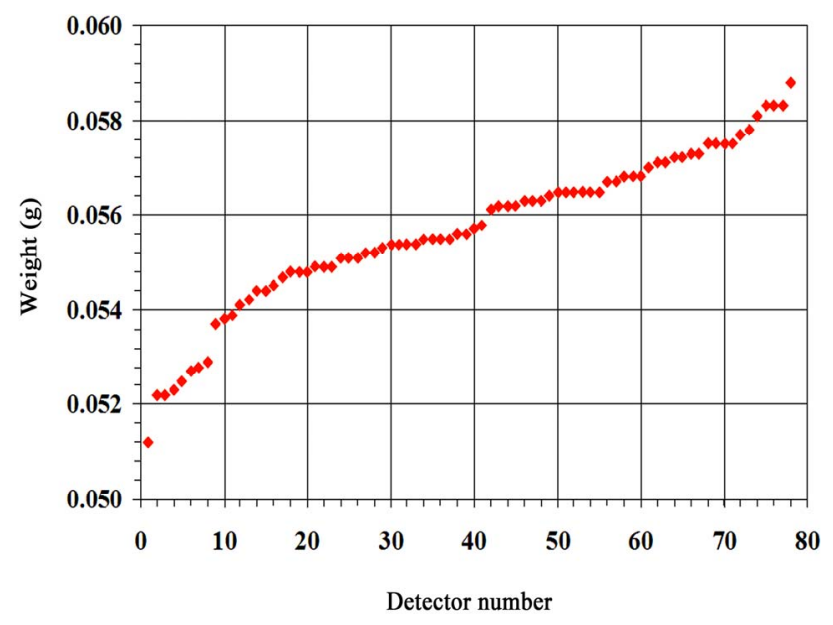

Figure 4. Masses (in g) of 78 different TLD-500 detectors.

Transmittance of TLD500

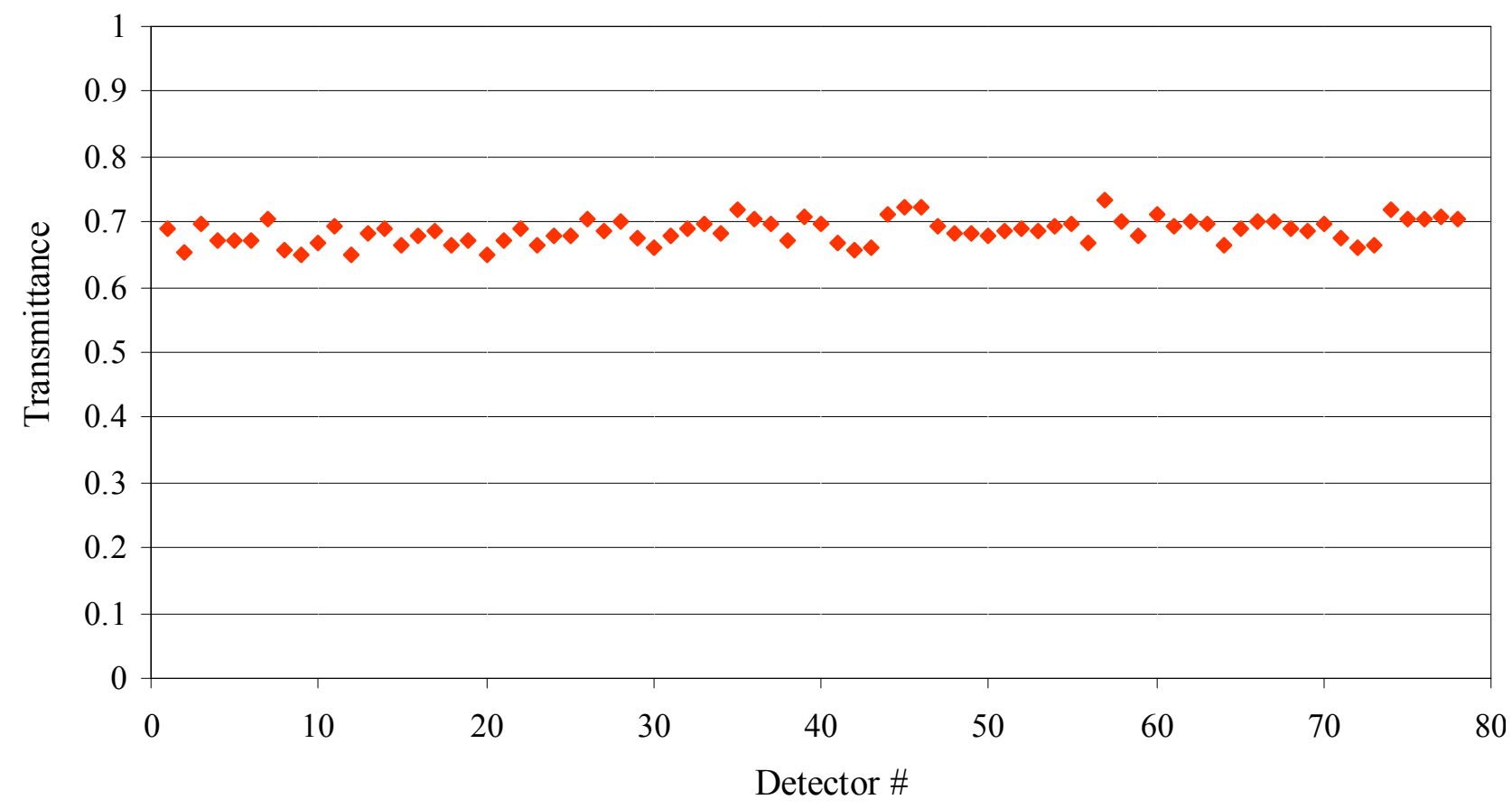

Figure 5. Transmittance of 78 different TLD-500 detectors. 
Transmittance of Luxel ${ }^{(\mathrm{TM})}$

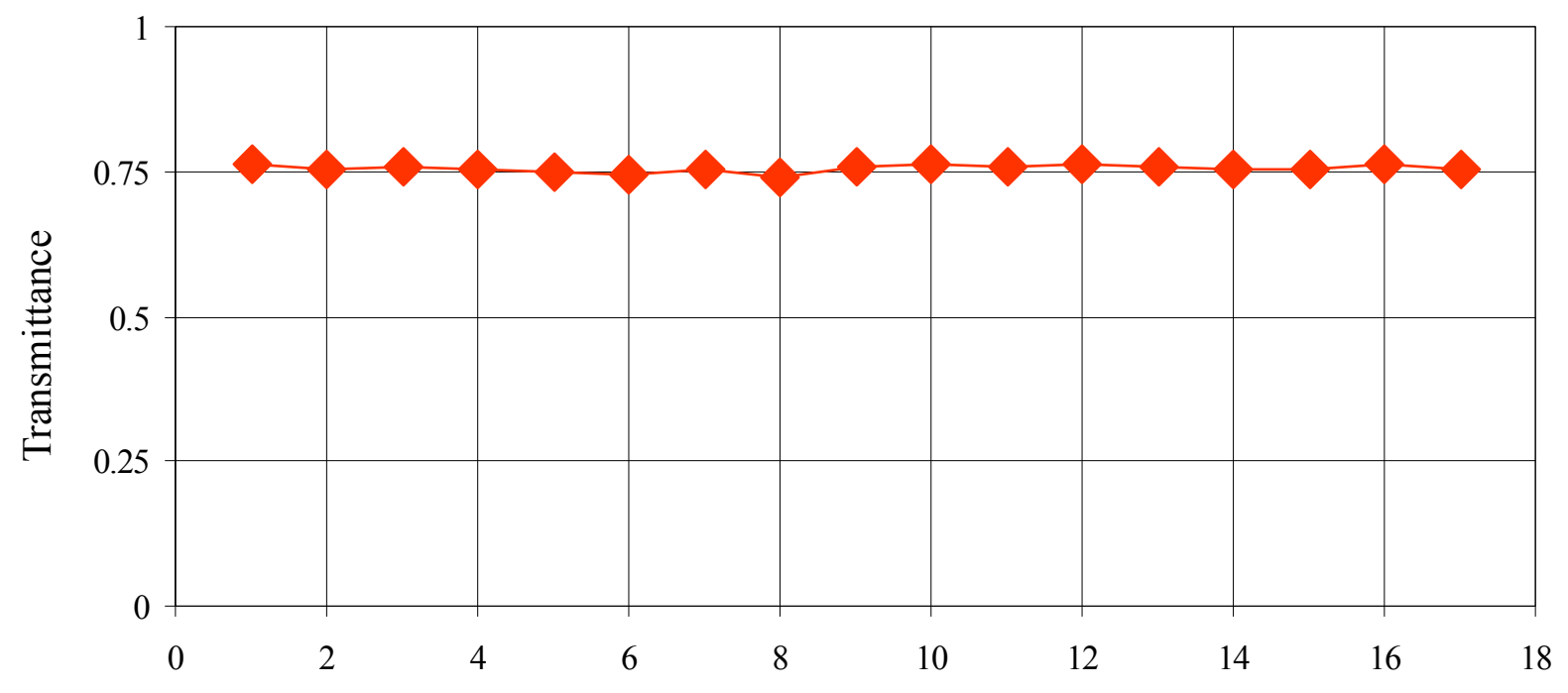

Detector \#

Figure 6. Transmittance of 17 different Luxel ${ }^{\mathrm{TM}}$ detectors.

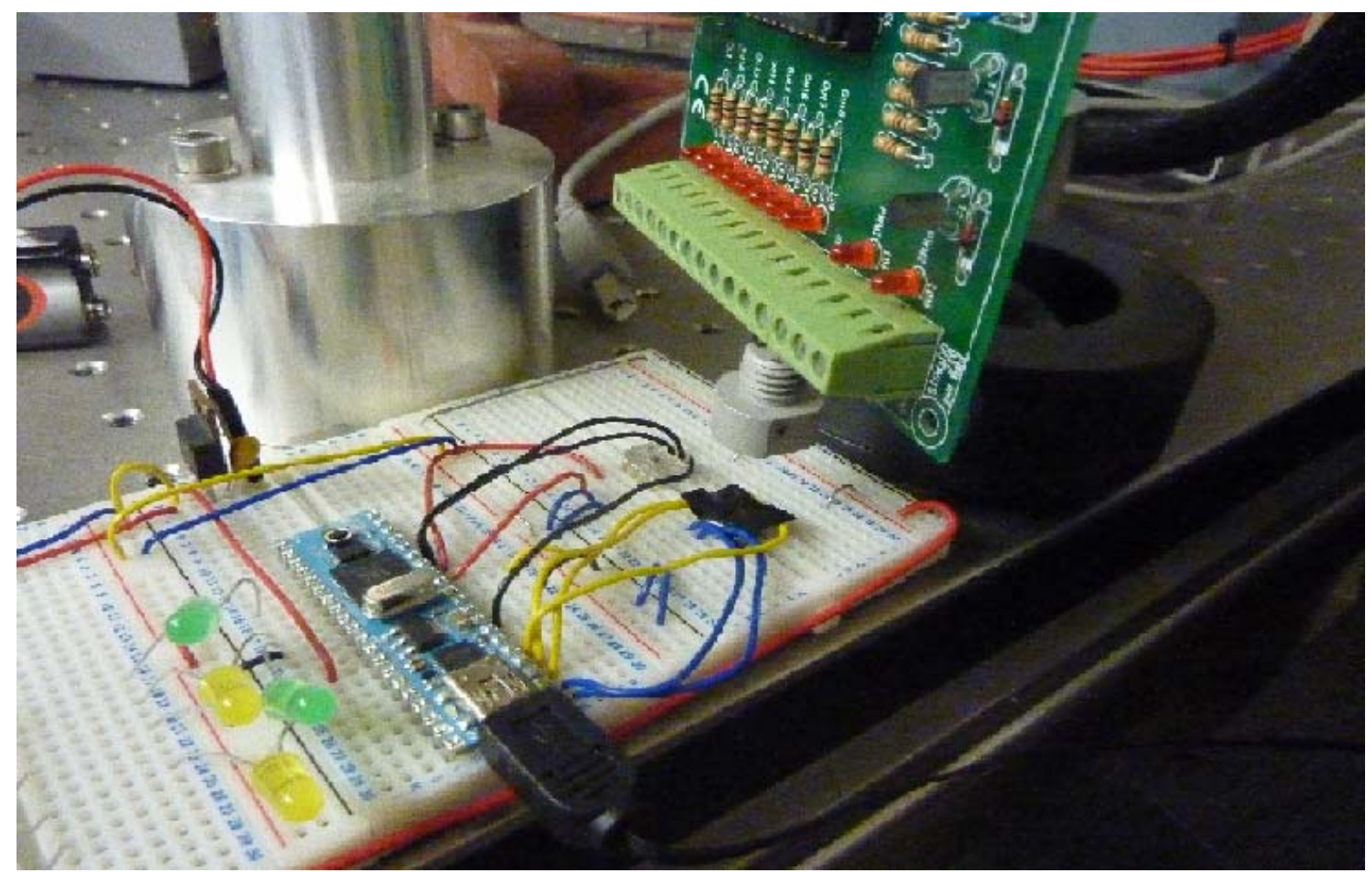

Figure 7. Mockup for the measurement of the attenuation coefficient of detectors used in OSL dosimetry.

The higher thickness of the TLD-500 with respect to the Luxel ${ }^{\mathrm{TM}}$ leads to another difference between the two detectors when they are read in transparency mode. Figure 8 shows that when a TLD-500 is reversed during the measurement, more signal can be collected from the other side of the crystal. This effect is not visible with the Luxel ${ }^{\mathrm{TM}}$ detector (upper curve). These results show that there is an optimal thickness of the detector when it is read by transparency. This thickness is calculated from the attenuation coefficients of the material, for the two wavelengths implicated in the OSL process, with the following relation: 


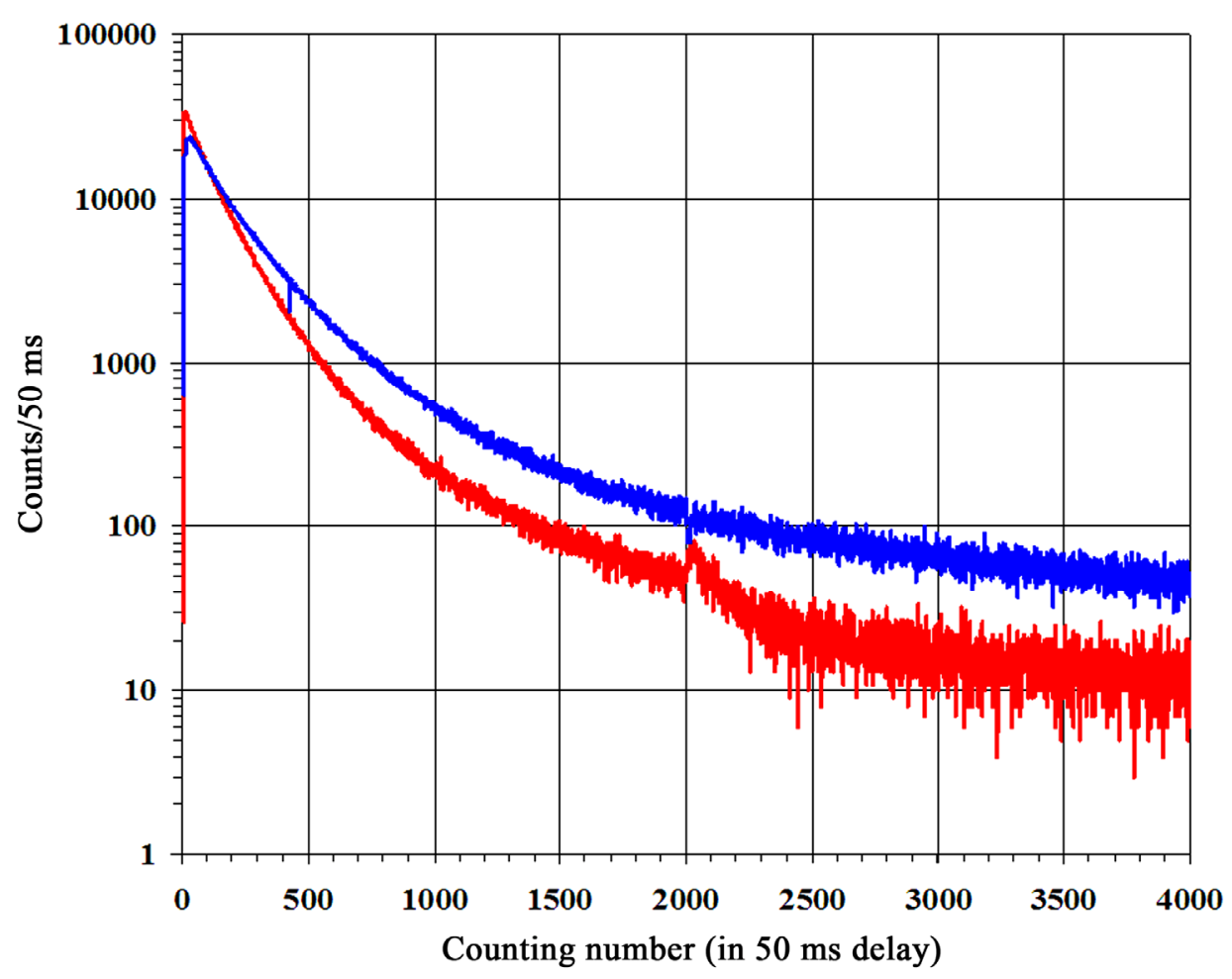

Figure 8. Effect of Recto/Verso measurement on TLD-500 detector (lower curve) and on Luxel ${ }^{\mathrm{TM}}$ detector (upper curve).

$$
I=\frac{I_{0} \cdot k}{\mu-\mu^{\prime}}\left(e^{-\mu^{\prime} \cdot t}-e^{-\mu \cdot t}\right)
$$

where: $I$ is the measured intensity of light emitted by the detector; $I_{0}$ is the stimulation light intensity; $k$ a factor considering all other losses; $\mu, \mu^{\prime}$ the extinction coefficients for stimulation light and for stimulated light respectively; $t$ the thickness of the detector.

Fifty detectors have been measured with the device described in Figure 7 using two different wavelengths. The measured extinction coefficients are $2780 \mathrm{~m}^{-1}$ and $3070 \mathrm{~m}^{-1}$ for blue $(465 \mathrm{~nm})$ and UV $(395 \mathrm{~nm})$ respecttively. These values introduced in the previous relation give the curve $I / I_{0}$ for different thicknesses presented in Figure 9. The optimal thickness for $\alpha-\mathrm{Al}_{2} \mathrm{O}_{3}: \mathrm{C}$ is $3.4 \mu \mathrm{m}$. This value explains the effects seen in Figure 8 and the advantage of the Luxel ${ }^{\mathrm{TM}}$ type.

\subsection{Characteristics of the OSL Device}

LiF:Mg,Ti (TLD-100) detectors used at the SCK.CEN has a detection limit $\mathrm{L}_{\mathrm{D}}$ of $50 \mu \mathrm{Gy}$ and a 7 decades dynamic range. $\mathrm{Al}_{2} \mathrm{O}_{3}: \mathrm{C}$ is able to detect doses as small as $20 \mu \mathrm{Gy}$ and presents an 8 decades dynamic.

Experiments showed that with this device, the detection limit is $7.2 \mu \mathrm{Gy}$ for the Luxel $^{\mathrm{TM}}$ and $6.5 \mu \mathrm{Gy}$ for the TLD-500. The Luxel ${ }^{\mathrm{TM}}$ is linear between 0.1 and $100 \mathrm{mGy}$, becomes sublinear between $100 \mathrm{mGy}$ and $1 \mathrm{~Gy}$ afterwards it saturates [6]. The reproducibility is $3.1 \%$ for Luxel ${ }^{\mathrm{TM}}$ and $8.4 \%$ for TLD-500 in OSL measurements. Each read-

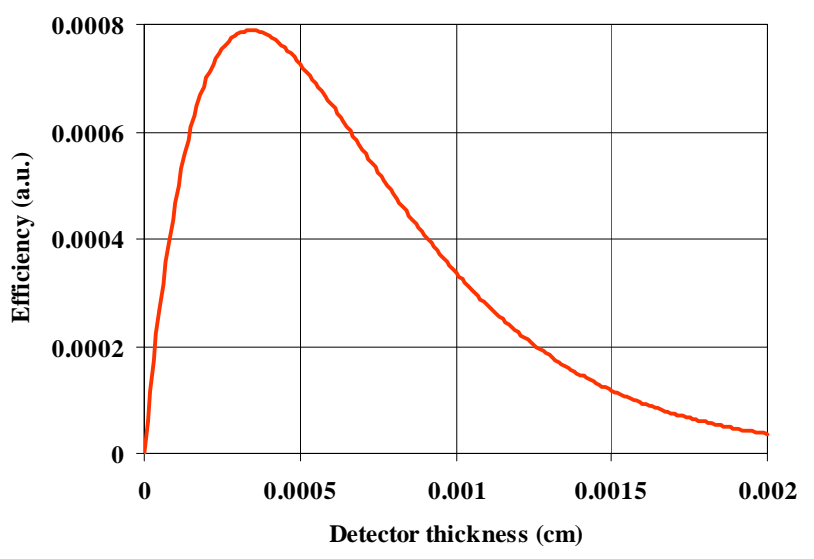

Figure 9. Evolution of the measured stimulated light from an $\mathrm{Al}_{2} \mathrm{O}_{3}$ :C detector versus its thickness for a constant stimulation light (Optimum thicknesses: $3.4 \mu \mathrm{m}$ ).

ing of an $\mathrm{Al}_{2} \mathrm{O}_{3}$ : C detector removes $0.2 \%$ of its sensitivity. For this reason and to avoid systematic errors due to loss of powder, the Luxel ${ }^{\mathrm{TM}}$ detector is preferably used only one time. This is possible because of its low price. The detector is first annealed with daylight through a window for about one day then used for the dose measurement and calibrated afterwards with a known dose. The detector is then discarded.

\subsubsection{Stability of the Measurement Device}

Different points are to be checked concerning the stability in an OSL measurement device: the stimulation light 
source, the stimulated light measurement device and the ambient light protection.

\subsubsection{The Stimulation Light Source}

The $\mathrm{Ar}^{+}$laser used in the device is characterized by an excellent stability of the output light intensity (better than $3 \%$ ). This stability has been controlled frequently and presented a problem only one time due to a defect in the power supply leading to oscillations in the light output power as shown in Figure 10.

\subsubsection{The Photomultiplier Tube}

It is well known that a PMT is quite sensitive to the ambient temperature. $\mathrm{The}^{+}{ }^{+}$laser device and its power supply are important heat generators so that the confined room of the laboratory must be cooled with an air conditioning system to guarantee a stable sensitivity of the PMT and accurate measurements.

\subsubsection{The Ambient Light Protection}

An OSL measurement requires a complete protection from the ambient light which is not easy to guaranty when the measurement of light is involved with a big laser which must be kept outside the confined volumes of the detector and the PMT for cooling.

\section{Applications of OSL Dosimetry}

The laboratory of Microbiology at SCK-CEN, in collaboration with different universities, participates in several
ESA programs related to bacterial experiments in space: research program MESSAGE (Microbial Experiments in the $\underline{\text { Space }} \underline{\text { Station }} \underline{\text { About }}$ Gene Expression) studied the effect of space conditions on micro-organisms in general using some well-known bacteria. During another experiment, MESSAGE 2, the samples and detectors stayed in space for ten days, of which eight were in the service module of the ISS. This dosimetry experiment was a collaboration between different institutes (School of Cosmic Physics, Institute for Advanced Studies, Dublin, Ireland, Johnson Space Centre Houston, USA, Department of Radiation Dosimetry, National Physics Institute, Czech Republic Department of Physics, Oklahoma State University, Stillwater, USA and SCK-CEN, Mol, Belgium), so that the doses could be estimated by different techniques. For the high LET doses $(>10 \mathrm{keV} / \mu \mathrm{m})$, two types of track etch detectors were flown. The low LET part of the spectrum was measured by three types of thermoluminescent detectors $\left({ }^{7} \mathrm{LiF}: \mathrm{Mg}, \mathrm{Ti} ;{ }^{7} \mathrm{LiF}: \mathrm{Mg}, \mathrm{Cu}, \mathrm{P} ; \mathrm{Al}_{2} \mathrm{O}_{3}: \mathrm{C}\right)$, and by the optically stimulated luminescence technique with $\mathrm{Al}_{2} \mathrm{O}_{3}: \mathrm{C}$ detectors, both in continuous and pulsed mode. The high LET results were of the order of $0.13 \mathrm{mGy}$ or $2.4 \mathrm{mSv}$ and LET spectra were obtained. For low LET radiations, small differences between different techniques and detectors were observed, ranging between 1.5 and $1.9 \mathrm{mGy}$, but a general agreement was observed. The differences may be generally understood from the different efficiencies of the different methods to heavy charged particles. OSL can find useful applications in retrospective dosimetry by measuring the tooth enamel for instance $[8,9]$.

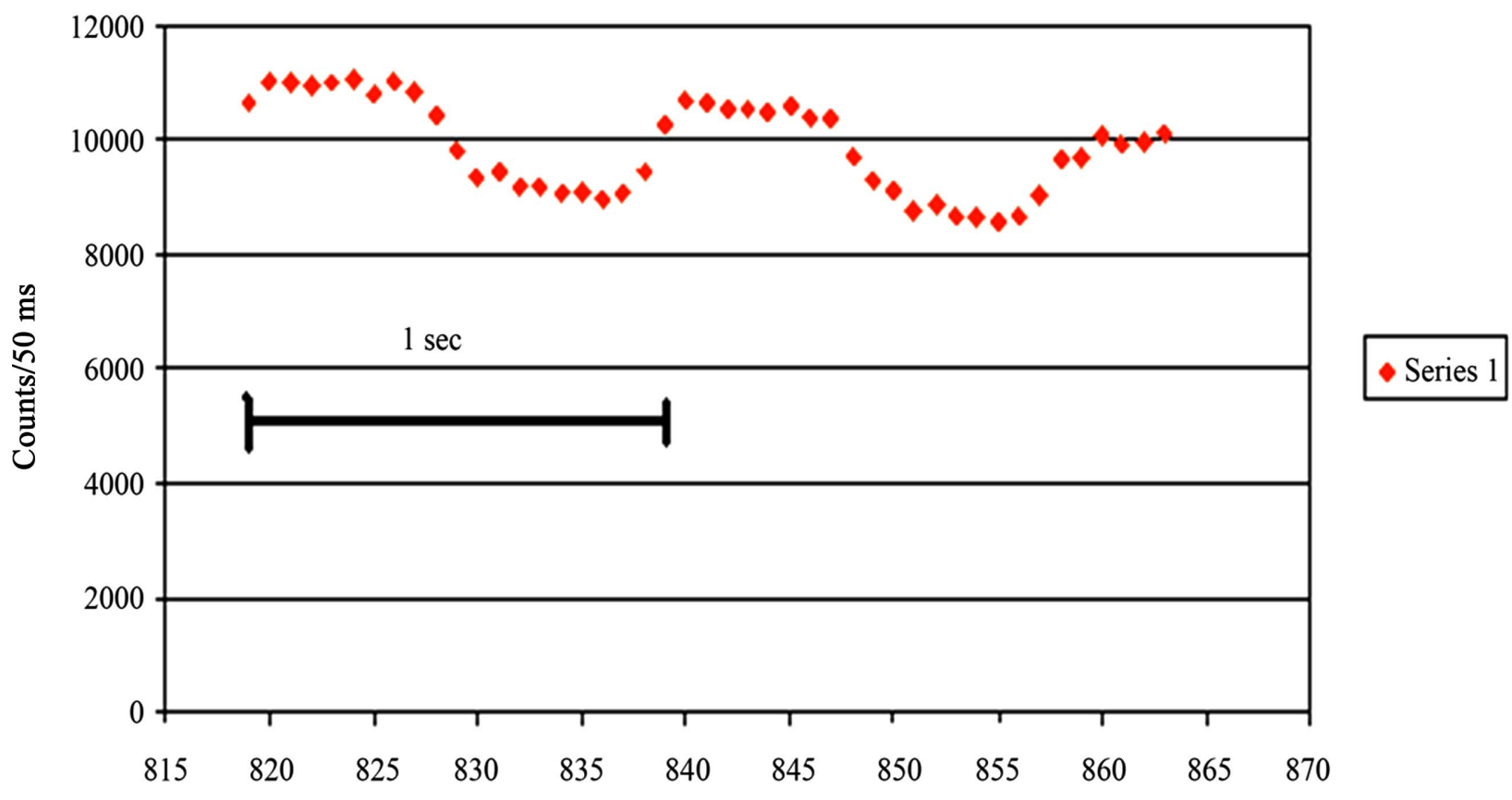

Counting number (in $50 \mathrm{~ms}$ unit)

Figure 10. Instability of the $\mathrm{Ar}^{+}$laser power output. 


\section{Future Developments}

The device using the $\mathrm{Ar}^{+}$laser has shown real interest as an OSL dosimetric tool but requires small improvements. Protection to ambient light and protection to mechanical vibrations has been the first points to improve. A future step will implement a simplification of the operations to change the detectors between measurements. The $\mathrm{Ar}^{+}$laser will also be replaced by a cheaper YAG laser with a frequency doubler or by a diode pumped solid state (DPSS) laser. This DPSS laser comprises a laser diode emitting in the infra-red domain followed by a frequency doubler to generate the green color best suited for OSL applications.A prototype of the modified device is shown in Figure 11. This laser is characterized by a short term instability of the beam intensity (Figure 12) followed by a very stable emission after about 10 minute (Figure 13). Peltier cells will be added to the reading device around the PMT holder to reduce the leakage current and keep the efficiency constant. The microcontroller driving the shutters will also be replaced by another one with other duties. The mechanical shutters have shown their utility also in pulsed OSL techniques [10] but they should be advantageously replaced by a Pockel cell or by a pulsed L.E.D. to improve the speed and allow different dynamical studies

\section{Conclusions}

The innovation brought by OSL techniques in the external dosimetry has extended the capabilities of the SCK.CEN in term of personal dosimetry, environmental surveys, space and retrospective dosimetry. The OSL dosimetry has been initiated with an argon laser with excellent detection limits and a very good reproducibility of measurements. It could be improved and easily extended to other excitation light sources (green laser diodes or high power LED's). The use of the $\mathrm{AL}_{2} \mathrm{O}_{3}: \mathrm{C}$ in the form of powder between two sheets of polyester (Luxel ${ }^{\mathrm{TM}}$ detectors) will improve the precision of the measurements. The cheap price of this type of detectors will allow the single use technique with appreciable reduction of interpretation errors.

In spite of the quality of the present device, it will be necessary to develop a device, more easy to use with selected green or blue L.E.D.s.
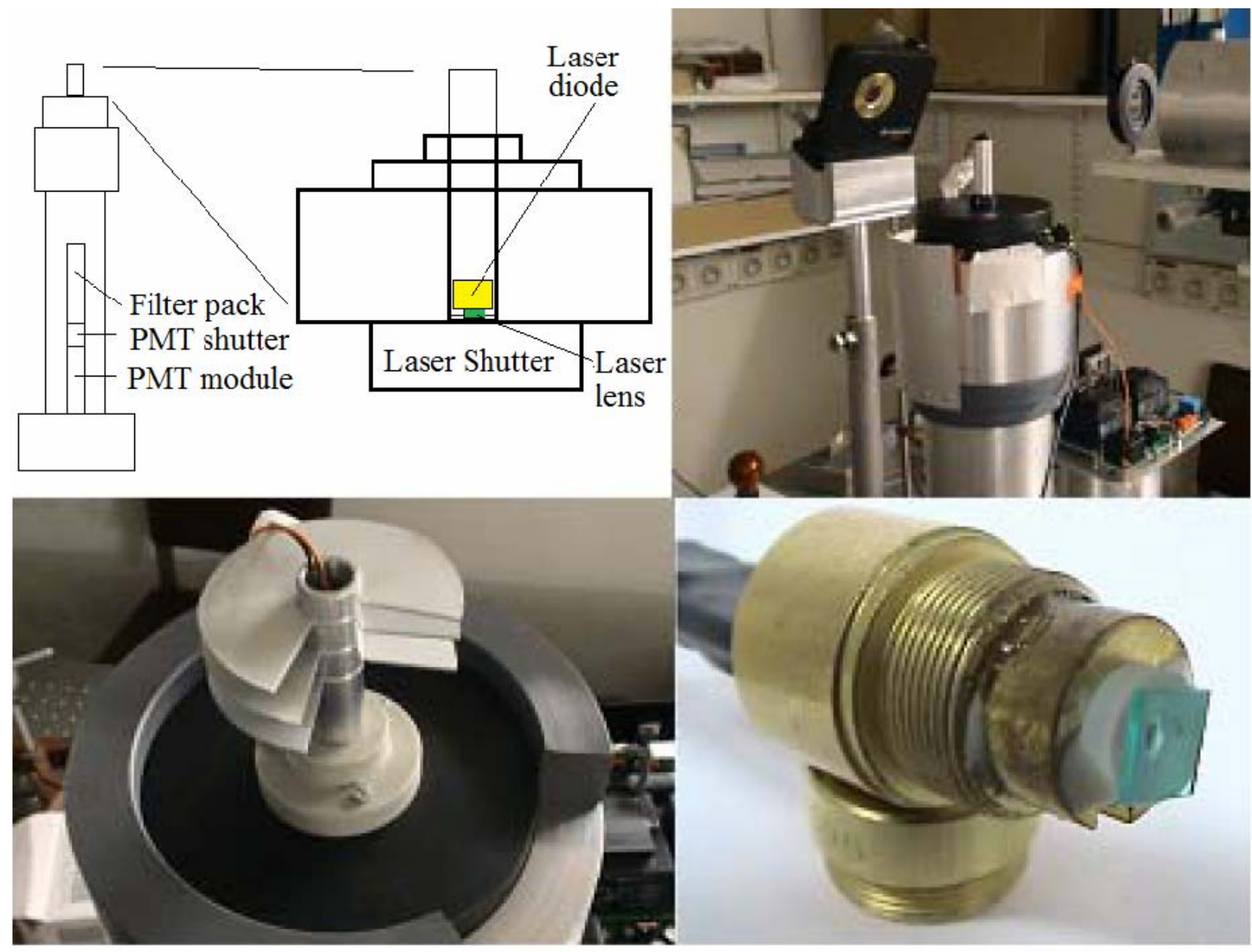

Figure 11. Description of the modified OSL device for stimulation with a DPSS laser. 
DPPSS Laser Stability

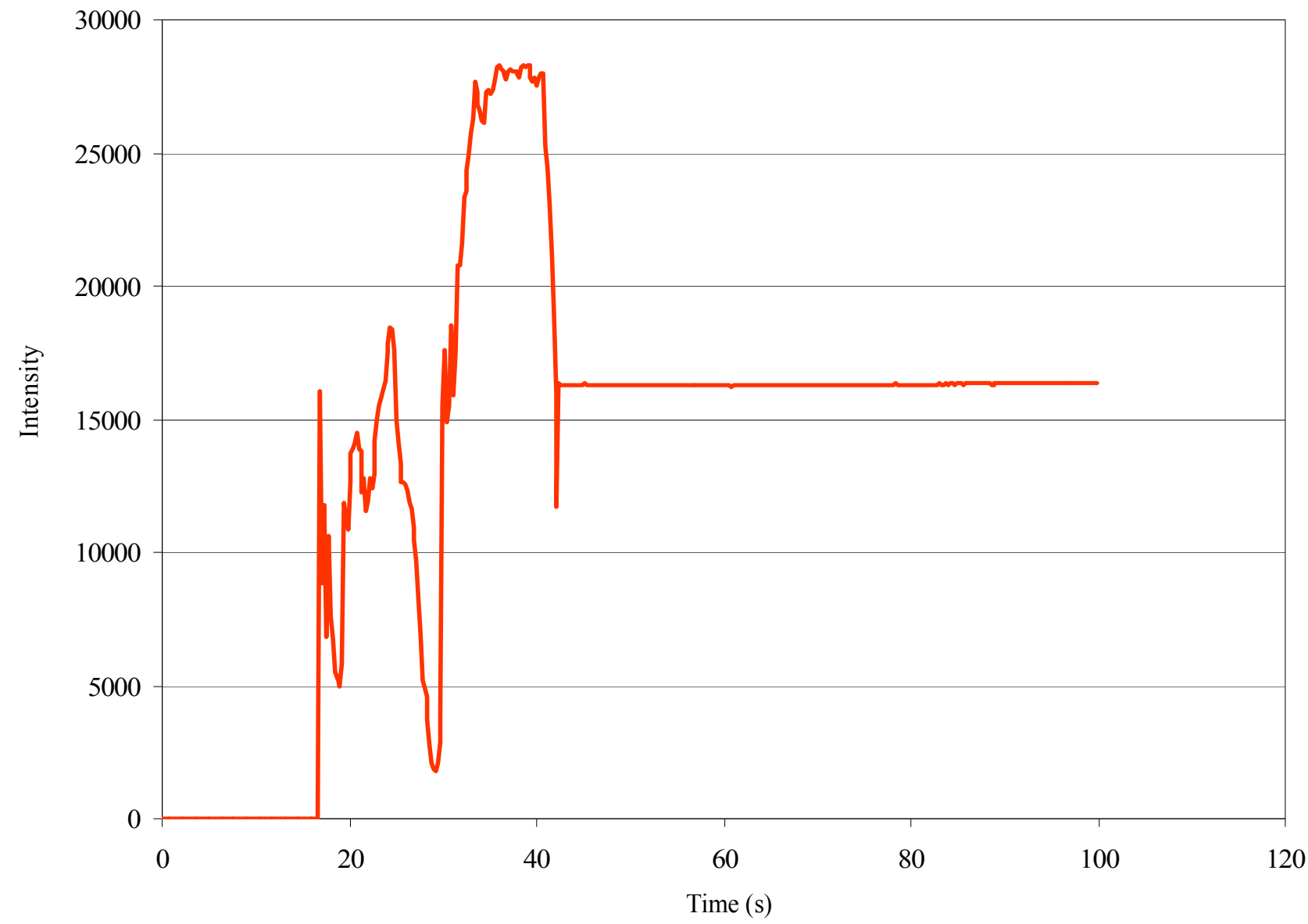

Figure 12. Laser output power after start up. The beam presents different multi-mode transverse before reaching a stable transverse mono-mode.

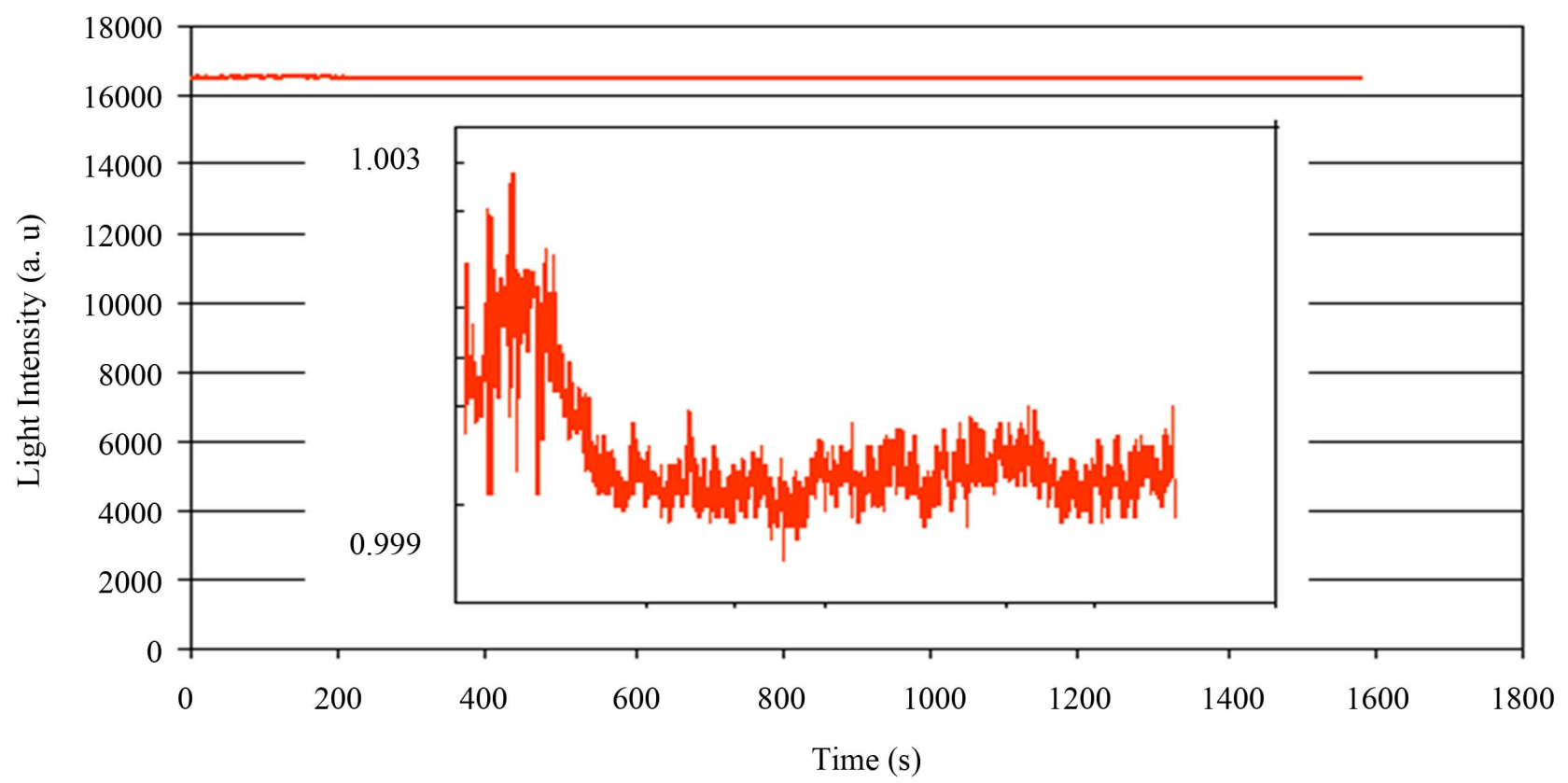

Figure 13. Stability of the DPSS laser 15 min after start-up and with cooling. 


\section{Acknowledgements}

For this work, we want to thank Dr. O. Goossens for his contribution in the first design of the OSL facility, B. S. T. Roggen for the different measurements in the characterization of the two types of sapphire detectors mentioned in this paper and measured with the Ar facility. We want also to thank M. J. Van Doninck for his continuous effort in different aspects in the development of the devices.

\section{REFERENCES}

[1] S. W. S. McKeever, M. S. Akselrod and B. G. Markey, "Pulsed Optically Stimulated Luminescence Dosimetry Using $\alpha-\mathrm{Al}_{2} \mathrm{O}_{3}$ :C," Radiation Proection Dosimetry, Vol. 65, No. 1-4, 1996, pp. 267-272.

[2] V. V. Antonov-Romanovskii, I. F. Keirum-Marcus, M. S. Poroshina and Z. A. Trapeznikova, "Conference of the Academy of Sciences of the USSR on the Peaceful Uses of Atomic Energy," USAEC Report AEC-tr-2435, Part 1, Moscow, 1956, pp. 239-250.

[3] H. Y. Goksu, E. Bulur and W. Wahl, "Beta Dosimetry Using Thin-Layer $\alpha-\mathrm{Al}_{2} \mathrm{O}_{3}: \mathrm{C}$ TL Detectors," Radiation Protection Dosimetry, Vol. 84, No. 1-4, 1999, pp. 451455.

[4] O. Roy, "Etude de la Luminescence Stimulée Optiquement (OSL) pour la Détection des Rayonnements: Application à un Capteur à Fibre Optique de Rayonnement $\gamma$," CEA Direction de l'Information Scientifique et Technique, 1998

[5] R. Chen, "Advantages and Disadvantages in the Utilisa- tion of Thermoluminescence (Tl) and Optically Stimulated Luminescence (OSL) for Radiation Dosimetry," IRPA Regional Congress on Radiation Protection in Central Europe, Dubrovnik, Croatia, 20-25 May 2001, pp. 1-8.

[6] S. W. McKeever and M. Moscovitch, "Topics under Debate-On the Advantages and Disadvantages of Optically Stimulated Luminescence Dosimetry and Thermoluminescence Dosimetry," Radiation Protection Dosimetry, Vol. 104, No. 3, 2003, pp. 263-270.

[7] N. K. Umisedo, E. M. Yoshimura, P. B. R. Gasparian, E. G. Yukihara, "Comparison between Blue and Green Stimulated Luminescence of $\mathrm{Al}_{2} \mathrm{O}_{3}: \mathrm{C}$," Radiation Measurements, Vol. 45, No. 2, 2010, pp. 151-156. doi:10.1016/j.radmeas.2010.02.001

[8] S. W. S. McKeever, M. W. Blair, E. Bulur, R. Gaza, R. Gaza, R. Kalchgruber, D. M. Klein and E. G. Yukihara, "Recent Advances in Dosimetry Using the Optically Stimulated Luminescence of $\mathrm{Al}_{2} \mathrm{O}_{3}: \mathrm{C}$," Radiation Protection Dosimetry, Vol. 109, No. 4, 2004, pp. 269-276.

[9] D. J. Huntley, D. I. Godfrey-Smith and M. L. W. Thewalt, "Optical Dating of Sediments," Nature, Vol. 313, 1985, pp. 105-107. doi:10.1038/313105a0

[10] D. I. Godfrey-Smith and B. Pass, "A New Method of Retrospective Radiation Dosimetry: Optically Stimulated Luminescence in Dental Enamel," Health Physics, Vol. 72, No. 5, 1997, pp. 744-749. doi:10.1097/00004032-199705000-00010

[11] J. L. Genicot, M. Moyaerts and W. Schroeyers, "Description of a Portable Devices Developed at SCK·CEN for OSL and TL Dosimetry," Radiation Measurements, Vol. 46, No. 12, 2011, pp. 1578-1581. 